\title{
Autism Spectrum Disorder: The Different Forms of Pharmacological Treatment
}

\author{
Gislei Frota Aragão* and Tatiana Paschoalette Rodrigues Bachur \\ University of the State of Ceara, Brazil
}

Submission: September 04, 2017; Published: November 16, 2017

*Corresponding author: Gislei Frota Aragão, University of the State of Ceara, Brazil, Tel: +55 85-98830-2494, Email: gislei.frota@uece.br

\begin{abstract}
Autism spectrum disorder (ASD) encompasses a group of neuro developmental disorders characterized by symptoms related to difficulties in social interaction and communication, as well as stereotyped and repetitive behaviors. To this present date, the treatment of ASD is based on the use of drugs, which help in the control of symptoms, and clinical manifestations that are quite heterogeneous, and there is still no cure for this pathology. The present mini-review aimed to describe the main therapeutic options used in the treatment of patients with autism spectrum disorders over the last 20years. It has been observed that the pharmacological therapy for ASD is based on the use of drugs developed for other disorders, and there are currently no specific treatments for the underlying disease, but only for the symptoms manifested, demonstrating that this disorder needs to be better understood for the success of research on new therapeutic options.
\end{abstract}

Keywords: Autism; Autism spectrum disorder; Pharmacological treatment

Abbreviations: ASD: Autism Spectrum Disorder; SSRI: Selective Serotonin Reuptake Inhibitor; US FDA: United States Food and Drug Administration

\section{Introduction}

Autism spectrum disorder (ASD) is a global developmental disorder characterized by behavioral changes and dysfunctions that include difficulty in communication and social interaction, as well as the presence of repetitive patterns of behavior, and restricted activities and interests. Other manifestations include phobias, sleep disorders, eating disorders and attacks of selfaggression and fit of rage [1]. Until this date, there is no cure for ASD, and the treatment of this disorder is based on the use of drugs that help control symptoms [1, 2]. For 20years, the therapeutic arsenal used included central nervous system stimulants such as methylphenidate, anxiolytics such as buspirone, mood stabilizers such as lithiumvalproate and carbamazepine, hormones such as melatonin, and glucocorticoids [3]. Currently, new drugs for pharmacotherapeutic treatment of autism have been introduced, while the use of others has been discontinued or kept $[4,5]$. This mini-review provides a brief presentation of the therapeutic strategies currently used for the treatment of patients with autism spectrum disorder, comparing them with the strategies used 20 years ago, and their impact on the quality of life of these patients.

\section{Discussion}

Initially described by Leo Kanner as an "autistic disturbance of affective contact" in 1943, autism spectrum disorder remains, until the present days, a disorder for which there is no cure but only the control of some of its clinical manifestations [4,6]. In 1997, Rapin [3] compiled nine classes of drugs used for the symptomatic treatment of ASD patients at that time, emphasizing, however, that for many of these patients, there was no need for drug treatment, succeeding with other types of non-pharmacological interventions such as psychotherapy and therapy, being these interventions currently considered as gold standard for the treatment of behavioral symptoms in autism [2].

Among the drugs cited by Rapin in 1997, the use of many of them, such as methylphenidate, tricyclic antidepressants and selective serotonin reuptake inhibitors (SSRIs), is still observed after 20 years, although with the disagreement of some authors as to the benefits of these in front of the possibility of occurrence of serious adverse effects in these patients $[2,4,7]$. Methylphenidate, whose use in autistic patients has been described by Rapin in 1997, has still been used for the symptoms of attention deficit hyperactivity disorder in these patients, having as common adverse effects decreased appetite, insomnia and emotional access. More recently, atomoxetine has also been used to control these symptoms in autistic patients, being well tolerated and having as common side effects nausea, decreased appetite and fatigue [5]. 
Among the antidepressants previously used, tricyclics, such as clomipramine, are not well tolerated and there is insufficient evidence of their benefits to be recommended in the treatment of children with ASD [4]. Selective serotonin reuptake inhibitors, despite of their use, have been questioned today, since a recent systematic review has indicated the existence of evidence of the ineffectiveness of this class of antidepressants in autistic children, as well as the possibility of serious adverse effects [8]. Currently, the US Food and Drug Administration (FDA) approves only two drugs to treat the symptoms of autistic patients: the antipsychotics risperidone and aripiprazole, drugs not used in 1997, more recently appearing as an alternative for the control of irritability, aggressiveness, self-injury and fits of rage in children with autism spectrum disorder [4,9]. These antipsychotics, however, should be reserved for patients with severe behavioral problems and their use should be made with caution because of the possibility of metabolic effects that include weight gain, dyslipidemia and hyperglycemia, in addition to sedation $[4,10]$.

A recent review study has shown different pharmacotherapeutic targets that may become potential treatment for autism spectrum disorder and seek to identify molecular pathways and cellular processes involved in autism. Among the therapeutic targets described, we have neurotransmission systems, in which drugs like antipsychotics (risperidone and aripiprazole) act signaling pathways in which rapamycin and its derivatives have been investigated as potential treatment for autistic patients; and the pathway involving neuromodulatory systems, with oxytocin as an example of a drug that may play an important role in social interaction in these patients [9].

Ousley \& Cermak [11] highlight the clinical heterogeneity of patients with autism spectrum disorder, which represents a great challenge for the identification of effective treatments, and an important target for research in autism is the search to minimize this heterogeneity through the best characterization of the patients and thus identify the best treatment for the subgroups. Eapen et al. [9], also focus on the genetic heterogeneity of autistic patients as a factor that impedes the therapeutic intervention in these patients, while suggesting that studies related to the elucidation of genetic variants may bring advances in the pharmacological therapy of patients with autism spectrum disorder.

\section{Conclusion}

Since ASD has been described, pharmacological treatment of this disorder has been carried out with drugs developed for other disorders in an attempt to control symptoms that may manifest themselves to a greater or lesser extent in the autistic patient. A better understanding of this neurodevelopment disorder, as well as elucidation of the molecular mechanisms involved, are essential for the development of new, more specific and effective drugs.

\section{References}

1. American Psychiatric Association (2013) Diagnostic and statistical manual of mental disorders. ( $5^{\text {th }}$ Edn.), American Psychiatric Association, Washington, DC, USA, p. 992.

2. Masi A, DeMayo MM, Glozier N, Guastella AJ (2017) An overview of autism spectrum disorder, heterogeneity and treatment options. Neurosci Bull 33(2): 183-193.

3. Rapin I (1997) Autism. N Engl J Med 337(2): 97-104.

4. Ji NY, Findling RL (2015) An update on pharmacotherapy for autism spectrum disorder in children and adolescents. Curr Opin Psychiatry 28(2): 91-101.

5. Lai MC, Lombardo MV, Baron-Cohen S (2013) Autism. Lancet 383: 896910.

6. Kanner L (1943) Autistic disturbances of affective contact. Nervous child 2: 217-250.

7. Hurwitz R, Blackmore R, Hazell P, Williams K, Woolfenden S (2012) Tricyclic antidepressants for autism spectrum disorders (ASD) in children and adolescents Review. Cochrane Database Syst Rev 3: CD008372.

8. Williams K, Wheeler DM, Silove N, Hazell P (2013) Selective serotonin reuptake inhibitors for autism spectrum disorders. Cochrane Database Syst Rev 8: CD004677.

9. Eapen V, Nicholls L, Spagnol V, Mathew NE (2017) Current status of biological treatment options in autism spectrum disorder. Asian J Psychiatr 30: 1-10.

10. Hirsch LE, Pringsheim T (2016) Aripiprazole for autism spectrum disorders ASD Review. Cochrane Database Syst Rev 6: CD009043.

11. Ousley 0, Cermak T (2014) autism spectrum disorder: defining dimensions and subgroups. Curr Dev Disord Rep 1(1): 20-28.

\begin{tabular}{|l|}
\hline \multicolumn{1}{|c|}{ Your next submission with Juniper Publishers } \\
will reach you the below assets \\
- Quality Editorial service \\
- Swift Peer Review \\
- Reprints availability \\
- E-prints Service \\
- Manuscript Podcast for convenient understanding \\
- Global attainment for your research \\
- Manuscript accessibility in different formats \\
( Pdf, E-pub, Full Text, Audio) \\
- Unceasing customer service \\
Track the below URL for one-step submission \\
https://juniperpublishers.com/online-submission.php \\
\hline
\end{tabular}

